\title{
Chapter 9 \\ Social Innovations as Messages: Democratic Experimentation in Local Welfare Systems
}

\author{
Adalbert Evers and Taco Brandsen
}

\subsection{Social Innovations as Messages-an Approach and a Metaphor}

The aim of this contribution is a twofold one. First of all, we want to present in a concise manner what kind of inspiration can be derived from the 77 local social innovations in the 20 cities that have been analysed in the welfare innovations at the local level in favour of cohesion (WILCO) project. What can be learned from them for the further development and restructuring of local welfare systems when dealing with the challenge of strengthening social inclusion? Secondly, we want to shed light on the procedural aspect of innovation - how can civil society actors, policymakers and administrators make better use of such social innovations, or to put it in more analytical terms, how to understand better the interaction between given social and welfare systems and innovations? With respect to both of these issues, innovative contents of cases and problems of diffusion of innovation, we propose to use the "message" metaphor.

First, let us briefly describe the empirical and methodological basis of this chapter. The introduction to this book already outlined roughly the concept of social innovation we worked with and the general method of analysis of the international research project. Therefore, we can restrict ourselves to point out the guiding orientations for selecting innovations.

First of all, we selected only local innovations that were past inception stage. According to this criterion, every innovation selected for investigation has existed for at least 1 year (since March 2011). Thus, all social innovations we looked at were

\footnotetext{
A. Evers $(\bowtie)$

Justus-Liebig University Giessen, Braugasse 7, 35390 Giessen, Germany

e-mail: Adalbert.Evers@uni-giessen.de

T. Brandsen

Department of Political Science \& Public Administration, Institute of Management Research, Radboud University Nijmegen, PO Box 9108, 6500 HK Nijmegen, The Netherlands e-mail: t.brandsen@fm.ru.nl

T. Brandsen et al. (eds.), Social Innovations in the Urban Context,

Nonprofit and Civil Society Studies, DOI 10.1007/978-3-319-21551-8 9
} 
about ideas or approaches that had already been implemented in practice to some degree. Each innovation selected by our teams entailed a practical project that had been realised. As it turned out, this project was either an organisation or an organisational subunit with new services that clearly differed from what existed so far in the field or a measure/intervention such as a new transfer, tax or resource arrangement. However, as the selected cases in this chapter show, local social innovations can also take other forms. Innovations always have a background of orientating streams of values and thinking as well as associated practices that back up and inspire them. A local network rather than a single organisational unit may represent innovations. Therefore, speaking about social innovations can refer to a large project, but also to a cluster of small, similar projects. In such case, the task was to describe the whole cluster and zoom in on one or two of the small cases, to get a sense of the micro-dynamics. In case the innovation was part of a government program meant to promote, finance and regulate an innovative approach, only those innovations from wider national programs that could be seen as "local", in the sense that there was a considerable degree of freedom to shape them in the local context, were selected. It was a mandatory requirement of WILCO to feature between three and six innovations in each city. The actual number of cases chosen in a city depended largely on the complexity of the respective cases.

Given the enormous diversity of social innovations, we suggested only three "analysis grids" for all teams to use when observing selected innovations. Hence, the selected case studies in this chapter have been organised along three basic themes: (a) conceptions and ways of addressing users, (b) internal organisation and modes of working, and (c) interaction with the local welfare system. Altogether, we tried to obtain both a very concrete and sensitive picture of the individual innovation and an intelligible way to draw "messages" that were interesting also for colleagues working on the issue in other countries and settings.

\subsubsection{The Concept of Messages}

What do we mean when we suggest understanding innovations as "messages"? First of all it means that beyond their immediate effect in the location where they take shape they may trigger similar actions elsewhere. In the field of welfare policies and services, which we studied, this may take the form of values and convictions that inspire them and which they want to promote, proposals they entail, and lessons to be learned. Obviously this calls for an analytical process of looking at the more general meaning of innovative ways of coping with problems that have come up recurrently in different local settings and circumstances. In the first part of this chapter, we will therefore present our reading of the messages implied in the innovations under study. References will be made to five dimensions of these innovations that we found especially telling.

However, understanding social innovations as messages also means looking at innovations as processes of transmission between actor and local context. Such a 
process can set a new practice into motion and address broader networks of civil society, political and administrative actors, possibly market actors as well. Are they willing to pay attention to such messages? What determines the different degrees of readiness among these actors to take up messages? And moreover, what influences the capabilities to "read" and the ways of interpreting them? All this may concern innovations and innovators themselves, the degree to which they actively care for broadening their action and winning support, but it mainly concerns contexts and the ability of systems - here welfare systems - to adopt innovations. The second part of this chapter will reflect on these questions, focusing on the difference it makes once an innovation is non-market based and in its essence non-technical, such as social innovations, taking shape in local milieus and welfare systems.

Obviously the metaphor of "messages" may in many ways be insufficient and questionable. Studies of innovation usually prefer the "diffusion" metaphor, and we also use it in this contribution. It takes account of the fact that innovations are a kind of "message into the open", without any specific or exclusive addressee. Many effects and messages of innovations are beyond the control of the innovators. However, speaking about "messages" has the advantage of including not only processes (of diffusion) but also issues related to content (new values, practices, policies). Furthermore, looking for "senders" and "receivers" allows us to study not merely systems and structures but also the actors who are responsible for dealing with a message, its contents and readings.

What are the main messages we found in the approaches and instruments used in local social innovations studied as part of the WILCO project? The first part of the chapter will deal with this question. What can be said about the processes of transmitting, accepting, rejecting or reading such messages (what is mostly called the process of diffusion)? What are the challenges when it comes to linking social innovations and social policies? This will be taken up in the second part of the chapter.

\subsubsection{Recurring and Shared Features of Welfare Innovations- Five Key Messages}

When analysing the cases of innovation, our aim was to find out whether there are recurring features that give them a distinct profile. Altogether they represent forms of acting and thinking that can be defined first of all in negative terms - breaking up with the traditions both of what we call "industrial welfare" and the more recent wave of managerial and neo-liberal reforms.

However, as we will show, these innovations can also be defined in positive terms. Recurring features point to a certain style of doing things, a shared culture and perspective of thinking and acting across national borders that makes a difference to the past. It was a key task of our analysis to deal with the question what can be generalised from these innovations, their approaches and the tools and instruments developed by them-not only in the special local system within which an innovation was taking place but also at the level of an international debate on 
local welfare systems, their institutions, rules, services, modes of governance and kinds of welfare mixes. Therefore we focused on commonalities and messages they entailed for the actors concerned, especially for policymakers, administrators and experts. Our findings (for a more detailed analysis of the findings presented in this paragraph see Evers et al. 2014 and Evers and Ewert 2015) have been ordered under five headings:

- Ways of addressing users

- Regulations and rights

- Governance

- Methods of working and financing

- Challenges to framing welfare systems

Table 9.1 shows in which areas the main emphasis of the respective 14 cases is to be found, but it notes as well one or two other fields where the basically polyvalent social innovations can be seen as illustrative.

The innovative approaches found in above fields obviously do not represent a kind of social or political programme. Rather, they are messages in terms of a loose assemblage of elements of a kind of "cultural turn" in dealing with issues of welfare and more specifically social inclusion. Different political actors and parties can take up concerns and aspirations of innovations and turn their contents and uses into different directions. Therefore the following points listed will attain more precise meaning over time, according to the way wider social and policy context integrate them into their discourses (Schmidt 2010). Linking social and economic concerns or striving for more flexibility and personalisation, for example, can take on quite

Table 9.1 Five dimensions of local social innovation - the emphasis of the cases presented

\begin{tabular}{l|l|l|l|l|l}
\hline & $\begin{array}{l}\text { New ways of } \\
\text { addressing } \\
\text { users }\end{array}$ & $\begin{array}{l}\text { Innovations } \\
\text { in regulations } \\
\text { and rights }\end{array}$ & $\begin{array}{l}\text { Innovations } \\
\text { in governance }\end{array}$ & $\begin{array}{l}\text { Innovative } \\
\text { methods of } \\
\text { working and } \\
\text { financing }\end{array}$ & $\begin{array}{l}\text { Challenging } \\
\text { the local wel- } \\
\text { fare system }\end{array}$ \\
\hline Warsaw & $\mathrm{XX}$ & & & & $\mathrm{X}$ \\
\hline Zagreb & & $\mathrm{XX}$ & & $\mathrm{X}$ & \\
\hline Amsterdam & $\mathrm{X}$ & & & $\mathrm{XX}$ & \\
\hline Lille & $\mathrm{X}$ & & $\mathrm{X}$ & $\mathrm{XX}$ & $\mathrm{X}$ \\
\hline Pamplona & & & & $\mathrm{X}$ & $\mathrm{XX}$ \\
\hline Berlin & $\mathrm{X}$ & & $\mathrm{X}$ & $\mathrm{X}$ & \\
\hline Milan & $\mathrm{X}$ & $\mathrm{XX}$ & $\mathrm{X}$ & $\mathrm{X}$ \\
\hline Stockholm & $\mathrm{XX}$ & & & & $\mathrm{X}$ \\
\hline Nijmegen & $\mathrm{X}$ & $\mathrm{XX}$ & & & $\mathrm{X}$ \\
\hline Birmingham(1) & $\mathrm{XX}$ & & & $\mathrm{XX}$ \\
\hline Birmingham $(2)$ & $\mathrm{X}$ & & $\mathrm{X}$ & $\mathrm{XX}$ \\
\hline Münster & $\mathrm{X}$ & $\mathrm{X}$ & $\mathrm{X}$ & & \\
\hline Barcelona & $\mathrm{X}$ & & $\mathrm{XX}$ & $\mathrm{X}$ & \\
\hline Bern & & & $\mathrm{XX}$ & & \\
\hline
\end{tabular}


different meanings. We will take up the importance of (discursive) contexts and the different faces of "mainstreaming" innovations in the second part of this chapter.

\section{Message One-About New Ways of Addressing Users}

The majority of social innovations chosen for inclusion in the study were service innovations. Since services are generally organised along less-closed and standardised lines than income transfer (for example, in pensions systems), it is little wonder that they provide more fertile ground for small-scale innovations.

The overall message of finding new ways of addressing users shows itself primarily in the search for new service relationships that reduce the dependency of users and strengthen their capabilities by opening up new opportunities or enhancing their skills. The theoretical debates on co-production (Verschuere et al. 2012) find a good illustrative counterpart in many of the case studies presented in this chapter. The orientation towards users and citizens featured in these cases implies a desire to avoid stigmatisation. Most of the occupational and social integration programmes provided as part of workfare policies (Handler 2004) employ strict targeting that clearly indicates who is "in" and who is "out", along with detailed rules and requirements governing the process of admission and integration. For instance, being entitled or forced to take part in a special programme for the long-term unemployed is linked with various forms of categorisation, classification and control. By contrast, many of the innovations addressing issues such as occupational and social integration take a more loose and open approach that does not impose admission requirements on (potential) users and does not prescribe in detail how reintegration should proceed and which stages it should include.

While public administration and welfare bureaucracies are separating between different tasks, needs and groups, it has become increasingly difficult to adequately meet the complex and often unique needs of customers in a highly segmented system. Bundling existing support measures tends to be complicated and discouraging. However, among the selection of innovations studied, there were a number of organisations that developed personalised support packages that allow access to otherwise separate forms of support.

Cultural and ethnic diversity and the problems of poverty and social exclusion have increased in the age of large-scale migration, unemployment and growing inequality. This makes it increasingly difficult for services and professionals to reach groups that need their help most, often because the services offered are simply not known, are too difficult to understand or are not taken up due to a lack of trust. Finding innovative ways of bridging the gap between professional services and real people's lives has been a recurrent challenge met by innovations we studied.

The various features of a different approach to users just mentioned is nicely illustrated in one of the case studies in this chapter about an innovative network providing new forms of support for children and single mothers, often vulnerable and living under stressful socioeconomic conditions. It was set up by a Swedish association operating mainly in the Stockholm area (see: Nordfeldt et al. in this chapter). The services that address children encourage group formation and shared activities while simultaneously organising individualised support in the form of fairs where mothers receive personal counselling by invited experts from different fields. 


\section{Message Two-About Innovations in Regulations and Rights}

These days, working and living patterns are changing and less continuous; zones of transition between life situations and life stages are becoming more complicated (Bovenberg 2008). Traditional services cannot always cope with these complexities. This may mean being out of school but not yet in a job, on the track back to employment but without access to a place to live. Often this coincides with other acute problems that may require immediate help. What some have called "new social risks" (Bonoli 2005) cannot be dealt with using the manual of standard risks. Innovative ways of offering a quick fix, often provisionally, may well be the critical missing link when it comes to providing living and working arrangements that keep people "in the game". Quite a number of social innovations studied in the WILCO project involve establishing flexible forms of ad hoc support that meet newly emerging risks short-term. One telling example is the Welfare Foundation Ambrosiano in Milan, Italy (see Sabatinelli and Costa in this chapter), that supported individuals and families who were temporarily in need for various reasons (redundancy, illness and so on) through quick micro-credits, regardless of their previous or current type of employment contract and country of origin.

Traditionally, most public welfare services have the status of rights that are unconditional, insofar as they simply require a set of material preconditions to be fulfilled. A new tendency in welfare arrangements (see Evers and Guillemard 2013), particularly in the field of "workfare", is for clients to enter a form of contractual relationship in which the preconditions for support concern their future behaviour. This requires clients to take exclusive responsibility for themselves. Among the set of innovations studied, there were also other types of moves from rights to contracts, defining the notion of "giving something back for what one gets from society" more broadly. People received access to goods and services once they committed to doing something for others in the form of volunteer work or providing clearly defined personal support for vulnerable people in the community. One example of this is Time for a Roof, an intergenerational home-sharing service in Nantes, France (see Coqblin and Fraisse 2014 in: Evers a. o. 93). It offered cheap accommodation to students who entered into an intergenerational cohabitation arrangement.

\section{Message Three-About Innovations in Governance}

The social innovations under study all represented a combination of new social "products" and new social "processes", the latter term referring to the internal organisation of decision-making and interaction with the environment, the public, various stakeholders, social partners and political and administrative authorities. Many social innovations that seek to develop new kinds of services also have a governance dimension. However, for some innovations, influencing and changing the system of governance was their main goal (see Moore and Hartley 2009; Lévesque 2013). This is the case, for instance, in the Citizen's Agreement for an inclusive Barcelona. More than 500 participating entities in spheres such as the economy, culture, education, health and housing worked on a new participative governance structure (see Montagut et al. in this book). Likewise in Bern (see Felder in this chapter) where new integration guidelines that became mandatory for public stakeholders 
were developed through a cooperative process in a working group of administrators, experts and representatives of local NGOs.

Traditional service organisations and systems tend to focus almost exclusively on their respective special tasks, effectively functioning in silos (Boyle et al. 2010). Social innovations, by contrast, are characterised by bringing together what is separate-ideas, concerns or practices - fostering units and types of organisations that operate in a more embedded and networked way. A good example are the Neighbourhood Stores for Education, Research and Talent Development (BOOT) in Amsterdam (see Broersma et al. in this chapter), where teachers and students from universities cooperated with activists in a community development programme linking governmental, not-for-profit and business organisations.

Innovation also means addressing issues, concerns and related forms of selforganisation in a way that is more in tune with changing challenges and pressures. When it comes to women's concerns, networks such as the MaMa Foundation in Warsaw (see Siemieńska et al. in this chapter) or the association Parents in Action (RODA; see Bezovan et al. in this chapter) overcame the traditionally restricted focus on achieving the same role as men in a labour market designed for men. They gave certain groups a voice in the public domain, highlighting new concerns that were previously seen simply as private issues, exposing local systems that under both socialist and post-socialist regimes displayed little interest in the manifold challenges of care. In doing so, these initiatives raised awareness of new ways of working and family life and brought them onto the public policy agenda. These and other innovative projects were eager to discover new ways of organising debates, deliberation processes and types of publicity, in order to set agendas and establish a new consensus on priorities.

Building issue-based coalitions and partnerships can be seen as denser forms of networking, often concerned with raising awareness of a particular issue. Establishing these kinds of partnerships, which are both unified and plural, is an important and innovative aspect of policymaking and fostering participation in governance. In addition to examples from urban housing and neighbourhood regeneration, the already mentioned Foundation Ambrosiano in Milan in this chapter provides a good example of bringing together stakeholders from diverse social and political arenas: the municipality, the province, the Chamber of Commerce and Industry and the three main trade unions, binding them into a pluralistic yet coherent alliance.

\section{Message Four-About Innovative Methods of Working and Financing}

When innovation means dealing differently with a given challenge or pressure, this often involves ways of accepting and living with worsening material conditions. Innovative projects and organisations with precarious funding are affected all the more by trends to be observed in todays' labour markets: limited contracts that offer no security. Of course one could speculate that this is partly compensated by an atmosphere of creativity and cooperation, more positive stress than the one produced by hierarchies. Trust-based relationships may allow many of the various contributors to participate for a while and accept short-term contracts, secure in the knowledge that a new contract is possible once circumstances allow. Still, trust 
building, cooperation and unwritten rules of respect can hardly be regarded as a reliable antidote to missing job security.

Furthermore, models for taking part in social innovation projects are typically much more diverse than in the public or business sector since they include not only various forms of (casually) paid employment but also many forms of voluntary and civic contributions. The latter range from short-term activism to regular long-term unpaid volunteering, from hands-on volunteer work to regular contributions in the form of civic engagement on a board of management. Hendrickson and Estany's contribution on Neighbourhood Children Services in Pamplona in this chapter is an illustrative example. This innovation provides leisure activities for children and young people such as activity groups, playgrounds, summer camps and neighbourhood festivals. In the working structure, one can find volunteers and paid practitioners from neighbourhood associations, cooperating with directors both of local social services and the associations themselves. For its network and activities, this combination of professional and lay contributions is indispensable.

People working in innovative projects must typically manage tasks that fall outside the limits of traditional professions and the divisions of labour that they imply (Brandsen and Honingh 2013). They might have to learn to converse with various kinds of users, clients, co-citizens and volunteers; sometimes they are specialists, entrepreneurs and managers simultaneously. Many of them need a combination of both technical and social knowledge. This kind of "re-professionalisation" process may, for example, involve collaborators who are architects by training but work simultaneously as community organisers and mediators. The social innovation based in a neighbourhood called Ilot Stephenson near Lille (see Fraisse in this chapter) features a group of architects supporting inhabitants in renovating their own houses under the slogan "Faire ensemble, le grand ensemble" (roughly translated: "working together to build the whole urban area"). This is a good example of a new kind of professionalism that combines previously fragmented knowledge.

Many, if not the majority of the social innovations we studied, are based on combining multiple sources of funding. The mix varies, and often state financing remains the most important component. But usually there is some degree of (financial) co-responsibility on the part of other organisations from civil society and/or the business sector. Furthermore, funding arrangements are usually precarious and limited in time. Examples of the possibilities and limitations of innovative projects that work with short-term funding, combining resources from different stakeholders, can be found in many innovations presented in this book (see, for instance, the contribution on work corporations in Nijmegen and their resource mix).

\section{Message Five-About the Need to Question How (Local) Welfare Systems are Framed}

The WILCO project sought to examine the possible contributions of social innovations to changes and developments in local welfare systems. It was understood that this label meant more than just local welfare-state institutions. Referring to a welfare system usually means including - in addition to the local welfare state and municipal welfare - welfare-related activities and responsibilities from the third sector, the market sector, communities and the family (Evers and Laville 2004). 
The cases of social innovations we examined demonstrate the mutual relationships that exist between all four components of (local) welfare systems - (local) state, business, third sector and informal networks of community and family life. There was considerable variation in the level and impact of state funding and support for social innovations. The organisations involved often took on a hybrid character (see, e.g. Fledderus et al. in this chapter). Social innovations can therefore best be captured by concepts of welfare based on deliberate mixing and pluralism among actors, resources and responsibilities.

Innovation becomes difficult, if not impossible, wherever the right to act, organise or provide differently is denied. This can be the case in both large private-sector business organisations, which are managed centrally, and in certain market sectors that are controlled by private sector oligopolies. Hence, giving room for social innovations often implies aiming for more diversity and more localisation in welfare arrangements. What is more, supporting innovation means opting for arrangements that allow a new balance between guaranteed equal standards and diversity.

It is no coincidence that the social innovations considered in this chapter are largely located at the intersection of welfare and urban development. Traditionally, local and urban politics have been less prominent in the system of public policymaking. This is likely to change, as Barber (2013) recently argued. Policy fields that are usually excluded from the welfare system, such as environmental policy or cultural activities, play an important role in socially innovative developments. As Brookes et al. show in this chapter, Birmingham operates with a locality approach to worklessness, where the packages of employment, skill-development and social integration measures are developed and tailored on "ward" levels (neighbourhoods of about 30.00 inhabitants), turning work integration programs into community-led, neighbourhood-specific approaches. The program "Kreuzberg acts" (see Ewert and Evers in this chapter) and the Ilot Stephenson project from Lille are also focusing on neighbourhoods, bringing together issues of individual consultancy and concerns with community revitalisation by networking and trust building among local stakeholders.

All these examples illustrate another major aspect of many social innovations: the upgrading of the community component in mixed welfare systems and of the development of innovative forms operating at the interface of public and community spheres, sharing responsibility between the two.

In contrast to most of the previous points, the integration of social and economic logics is much better established as a concern in debates on future welfare systems. The economisation of all spheres and an increasing focus on productivity are one side of the coin. On the other, there is the debate on the welfare state as a "social investment state" (Morel et al. 2012). This advocates modernising public welfare through an approach that stresses the positive economic effects of social policy intervention in education, family support, and in occupational and social integration. In urban regeneration, social innovations seeking to combine the active participation of people as co-producers and co-decision-makers with public and private investment can be seen as part of this perspective on social investment as a means of societal development. 
Summing up, the local innovations we observed — besides specific tools and aims mentioned before-represent an important way of reconfiguring mixed welfare systems, an observation likewise made by Jenson (2013) who even argues that this might be their main role.

\subsection{Sending and Receiving - the Diffusion of Social Innovations}

The following part discusses our analysis of diffusion processes. The sample of social innovations studied in the project is not quantitatively representative of diffusion potential, which makes firm statements on how much diffusion occurs impossible (which is, in any case, very difficult methodologically). Furthermore, the focus was on relations within the local context. However, the broad variety of types of innovations, the nature of which has been sketched in the first part of this chapter, allows us to draw some analytically generalizable conclusions concerning the nature of the process. We will focus on aspects of the process that are most distinctive of social innovation and on those specifically relevant to the third sector. We will continue to use the metaphor of sending and receiving messages.

Basically this metaphor, with its strengths and shortcomings, can be used for all kinds of innovation: market- or non-market-based, those technical in nature, others that are more about organisational devices and those concerning social relations and lifestyles. One should however recognise the special nature of this final type of social innovations (non-market-based and non-technical), which mostly develop at the local level in specific places (Zapf 1989). They have some distinctive features compared to innovations more generally. Specifically, three characteristics can be noted, which will be referred back later:

1. Social innovations usually relate to services, not products. As Osborne and Strokosch (2013) emphasised, this makes them different from other types of innovation in that they relate to ongoing relationships rather than discrete transactions and to outcomes rather than outputs.

2. As a consequence, this type of innovations is usually embedded in specific social relations. This, in turn, means that they are more contextually bound than their technological counterparts. An iPad will continue to function in the same way whether it is used in Stockholm, Dover or Belgrade. The same cannot be said of approaches or schemes that work with people and rely on specific regulations and cultures to be effective. This is very relevant to the issue of diffusion, as it becomes much more complicated both in terms of objectives and process. Innovations invented in specific locations and setting cannot simply be "scaled up" as they require various ways of partial adoption and special readings.

3. Local social innovations address a specific type of need, a social need not yet sufficiently addressed by government programmes and markets. By implication, the majority are non-marketable. While many innovations originate from busi- 
nesses, most innovations in local welfare originate in non-market contexts and respective social milieus, like the voluntary sector or social movements (according to some definitions of social innovations, exclusively so). Their social character is specific. This again has consequences for processes of diffusion, scaling-up, popularising or mainstreaming.

Taking these specificities into account, we can sum up the problems with transferring messages from social innovations that surfaced during the research in six paragraphs.

\section{Risky Journeys: The Diffusion of Non-technical and Non-market-based In- novations}

The literature on the diffusion of innovations primarily concentrates on the business sector and therefore principally on diffusion in a market context. As we noted before, this is not the realm of all innovations, including most social innovations in the welfare domain, and we will see that it has consequences for the ultimate analysis of the process. Therefore it is useful to consider insights from literature outside market contexts.

There is by now a substantial body of literature on innovations in the public sector, under the label of "policy transfer". This work on policy diffusion examines how policies spread across different administrations, adapting (or not) to different institutional conditions (Dolowitz and Marsh 2000). For instance, it has been used to explain the diffusion of monetary policy across member states of the European Union with their own different formal structures and administrative cultures (Radaelli 2000) or the spread of public management practices across different countries, in which the same instrument or policy can have very different meanings depending on where they are implemented (Pollitt and Bouckaert 2004; Brandsen and Kim 2010).

Actual diffusion processes differ strongly in terms of what is diffused (e.g. objectives, contents, concepts, structures, instruments) and the degree to which something is diffused (ranging from straight copying to light inspiration, with various hybrid variations in between). Furthermore, it has to be kept in mind that journeys from "senders" to "receivers/adopters" are mostly risky and sometimes intricate (Nowotny 1997). There are many reasons why innovations may not diffuse from their place of origin. Others may get lost on the journey, damaged, changed in content or taken up and used by adopters other than innovators had thought of. While research on diffusion tends to focus on the process of adoption, especially of successful cases of adoption, one should ideally also examine failed cases or those cases where an innovation could have been relevant, but was never considered.

What also becomes more complex in a public context is the issue of motives for diffusion, which is straightforward (or at least presumed to be so) among commercial businesses. The incentives for policymakers and civil servants are more complex. While they can be driven by the desire for problem solving, they can also be motivated by political gain and/or complex political strategies. Hence, the question of motivation (or lack of it) is important in the analysis of the diffusion of social innovations. 
The literature also pays much attention to obstacles to diffusion that result from the nature of the innovation itself. In line with Rogers' work (1962), it suggests that the more complex innovations are (in terms of goals, assumed causalities, effects) the harder it gets to take them from one place to another. The more resilient the destination context (e.g. due to the strength of a dominant discourse or top-heavy regulation), the less likely it is to succeed. Transfer success also depends on capacity and resources available. The empirical results of the WILCO project show that the same applies to social innovations.

Even though there is an already burgeoning literature on innovation transfer, questions about what is specific about the diffusion of social innovations remain. Non-technical and non-market-based innovations are generally more diverse in terms of organisational properties or lifestyles compared to technical innovations designed for mass markets. Yet, to be fair, the difference is not always as drastic as the one between a cell phone and a new mode of participation in urban planning. Many new mass products are sold with varieties that allow marketing geared to the different tastes of consumers in different cultures and regions. Still, the differential impact of "local" as compared to "global" features remains an important topic for research to investigate what is specific for social innovations.

\section{Spreading Rather Than Being Sent: The Opaque Nature of Diffusion Pro- cesses}

When the process of diffusion is studied across a wider range of cases, the senderreceiver metaphor quickly becomes unsatisfactory as, however bad the connection, however confusing the conference call, one usually knows who is at the other end of the line. Not so for diffusion because the process is so hard to trace.

Johnson dealt with the difference between areas such as the business sector, where innovations can be formalised, sold or withheld by license, and the often taken-for-granted fact that most social innovations develop in the public realm where they are basically free for use (2010, p. 240 f.). However, one of our case studies (Ewert and Evers in this chapter) shows that in the social realm there is also a tension between diffusion by innovation as an "open source" and diffusion channelled by competition. Projects and organisations such as Lok.aMotion, dealing with innovative concepts for community development and community-based business in Berlin-Kreuzberg, must act under conditions of "co-ompetition" where cooperation and competition merge. They often feel that their concepts are not simply taken up, but "stolen".

This dilemma is hard to overcome because cases where a clear origin and "author" of a social innovation can be identified are hard to find. Many of the case studies presented in this book are innovative in the local place where they crystallise but resemble concepts and ideas elsewhere. This holds true for quite a number of innovations presented in this book: the essentials of work integration enterprises and the variant discussed with examples from Nijmegen, the prevention visits for improving local child protection in Münster (Walter and Gluns) or the housing revitalisation schemes from the outskirts of Lille (Fraisse). These are varieties within a national or international innovative stream and orientations. The fact that respon- 
dents attribute an innovation to a particular project or locality does not mean that it was necessarily the only or even the original source of an idea. Several similar schemes often pioneer in different places during the same period. While certain projects can be hailed as emblematic of a trend, it does not necessarily mean that they are the sole source of it.

Local social innovations that are not exclusive to one place show at least four different constellations:

(a) They may have a predominantly bottom-up character, promoted by third sector organisations and the cultural orientations of the specific environment they emerge from (see, e.g. the cases from Sweden and France in this chapter).

(b) They may develop through joint action in a cross-sectorial local network, where the initiative may come from "policy entrepreneurs" as local parties, policymakers and administrators, as in the cases from Bern and Barcelona.

(c) They may take shape as local varieties within a national programme or framework which experiments with new ideas and scales them up, as can be observed in Birmingham or Münster.

(d) Finally there are cases of social innovation in which the centre of gravity is located neither centrally nor locally but in nationwide civil society networks, as in initiatives such as the MaMa Foundation or the RODA network which started through Internet contacts (see Siemieńska et al. and Bežovan et al. in this chapter).

\section{The (Un)Willing Sender}

It is often taken for granted that the person who sends a message does so on purpose. In other words, we assume that the innovator has an interest in getting a message across. This makes perfect sense in a market context, where diffusion often results in profits. The social innovation literature stressing the entrepreneurial and leadership side of the phenomenon (e.g. Goldsmith 2010) and research on innovations in social movements (Moulaert et al. 2005) also assumes a strong will to "spread the message" and change the world.

However, the findings from the WILCO project show that many social innovations are generated by actors, often from the voluntary sector who have no direct interest beyond their local contexts. They concentrate on their immediate milieu, where they feel understood, encouraged and supported. A detailed look at cases in this chapter that concentrate on surviving and solidifying on the place where they operate such as the Fondazione Welfare Ambrosiano in Milano or the Neighbourhood Children Services in Pamplona shows that these are often groups of people or organisations that took action in the face of a pressing local need: Children went hungry, women were abused, young men wandered the streets aimlessly. They devoted great energy to get their initiative off the ground, scraping together resources and building on local knowledge (Scott 1998). "Selling" their innovation in another city, let alone another country, seems out of their reach and potential, therefore out of sight and thought.

This again points to the essential difference with other types of innovations. A company like Apple did not design its iPads for the local Californian market, but in the hope of selling them around the world. In fact, they would not have invested 
in the idea, had they not been confident that they could sell these devices in a great many places. By contrast, social innovations tend to have no market value, and there is no financial incentive to spread them. This does not mean that there are no incentives at all: Idealism and the search for a better social status can go a long way. Nevertheless, in Rogers' terms, many local innovations may be weak in the "knowledge" and "persuasion" phases of the adoption process. Both the active entrepreneurs, civic activists and leaders in social movements highlighted in much of the literature are just one group, and perhaps only a minor one, of social innovators in local welfare. Due to their concern with wider support and publicity, their importance tends to be overrated.

\section{Intermediaries}

However, that does not mean that there is necessarily a hard distinction between innovations designed only for use locally and those designed to be part of an (inter)national movement for social change and innovation. An important and related finding concerns the role of intermediaries (in Rogers' terms, the opinion leaders and change agents). More than other types of innovation, social innovations require intermediary agents for successful diffusion. They can be important for both: bringing ideas from the realms of politics and academia "down to earth", into realms accessible to local associations and projects and endorsing and passing over concepts and ideas from the "grassroots" to a larger public.

Among the cases of local social innovations presented in this book, a good example of such an intermediary organisation is Fryhuset, which has general competence in social action and advocacy, taking up and linking the special project on children and single mothers to other initiatives. Some of the innovations studied and presented in the following chapters, such as the MaMa foundation or the RODA network, focus foremost on this intermediary level. In both cases, there is no strict separation between nationwide concerns with innovative measures and steps towards legislation, on the one hand, and giving support to local groups and initiatives on the other. Intermediary action can also come from the side of governments, businesses, social enterprises and professional groups. In Poland, for instance, it was interesting to see the important role of lawyers. Dealing with a legalistic administrative culture, they were the right people to make the translation between bottom-up initiatives and government officials (see the resp. contributions on Polish social innovations such as "The foundation for the development beyond Borders" in Evers et al. 2014, p. 250).

\section{Writing Messages: The Process Prior to Transmission and Adoption}

A process of reconstruction and translation requires new ways of collaboration between governments and citizens, for example, as well as new ways of thinking. The empirical material in this book shows that in local welfare this process does not start with the adoption of an innovation adopted, but usually well before that. A good idea is not convincing in itself — only when people are open to it. What this means is that adopting an innovation from elsewhere is, from the perspective of the adopting parties, not fundamentally different from inventing one. After all, it requires similar breakthroughs in institutional routines, whether of content, collaboration or other 
aspects of working. Theoretically, it means that the analysis of diffusion must start before the actual adoption of an innovation.

The underlying question is to what extent the innovative capacity is reflected in what is adopted (a specific approach to solving a problem) or rather in the groundwork that is done before adoption (getting the right people together, getting minds ready for new options, and so forth). This is highly relevant to public administration reform because it means that simply finding the right kinds of policy approaches or instruments in itself is not enough.

However, instead of going into a chicken and egg controversy about the impact of "winds of change" and of innovations that both build on and promote them, the focus should be on the links between both phenomena. All case studies in this book illustrate such links one way or the other, which may to different degrees be mutually enforcing.

\section{Different Readings Merging: The Adoption of Innovations as Bricolage}

Sending a message the author usually hopes for it to find its destination with its content intact. It would be intolerable if someone took it and rephrased it in her or his own words. Yet this is exactly what must happen in a successful process of diffusion. It is rare for a certain project or approach to be copied from one place to another unchanged. If so, it usually concerns simple schemes that can be implemented more or less independently from regulation or policy and which require only limited collaboration between local actors. An example are the Neighbourhood Mothers, a Dutch scheme in which migrant women are used as intermediaries to counsel other migrant women (a notoriously difficult group for authorities to reach) on issues such as social security, healthy lifestyles and parenting (see for the case from Berlin: Evers et al. 2014, p. 124). Dealing with similar constituencies and relying on little regulatory support, it was a concept easy to spread.

This no longer works with more complex innovations in welfare, however, as they tend to deal with difficult social problems and difficult constituencies. Approaches or projects need to be adapted to new contexts, they call for changes in institutional routines and the values that guide them. The literature on diffusion in terms of "transfer" and "franchising" of special organisational concepts is missing many potential ways for "mainstreaming". Quite often processes of diffusion and mainstreaming entail mutual adjustment. The shape of a collaborative arrangement may have to be altered, for example, because responsibilities for a certain policy area are distributed differently in governments at different levels or because services are provided privately in one country and publicly in the other. The innovation will be reshaped, whether due to a different socio-economic and regulatory environment or for reasons of a different dominant policy discourse.

In many cases, the development of social innovations can be conceived of as a back and forth process between the characteristics of a social innovation and the specific environment of markets, state institutions and civil society into which they spread. The respective discourses (Schmidt 2010) through which the innovation is read, justified or rejected take a key role in this process. They influence the receptiveness of actors and contexts as well as the reading of and role given to innovations in local welfare systems. 
This process can be decoded with the set of basic "messages" we discussed earlier in this chapter: services that lead towards co-production rather than merely supplying; rules and regulations that upgrade the impact of a "quick fix", by referring to social rights that take a long time to take real shape; forms of governance that give a new role to stakeholders from civil society; patterns of governance that imply lower thresholds for the contributions of not only paid experts and politicians but also of civic activists, social entrepreneurs and volunteers; a different division of responsibilities between business sector, state institutions, citizens and their communities. Each of these messages points towards a different "culture" of welfare and social inclusion and can be read and interpreted quite differently, depending on the ideological and political discourses they are incorporated in.

In their seminal study on "The New Spirit of Capitalism", Boltanski and Chiapello (2005) have shown how "autonomy" and "flexibility", topics that emerged from the social movements of the early 1970s, were turned into centrepieces of justification for the restructuring of labour markets and conditions by businesses. This is a superb example of how aspirations and messages from social innovators can be read in different ways. They acquire different meanings, depending on the position given to them in the discursive context. This is testament to the open and risky nature of innovations. From such a process of mainstreaming, concepts such as "activation" and "empowerment" can emerge with different purposes and different meanings. They can relate to strengthening a sense of duty and commitment to goals set by the administration; alternatively, they can refer to strengthening capacities for individual and joint action, activating not only individual competence but also sources of support and solidarity. The study on prevention visits in families in the city of Münster in this book describes the controversy at the outset of this innovation whether to develop it as a special measure for troubled families only or as an open offer to families more widely. In the case of Neighbourhood Children Services in Pamplona, innovative association-based approaches received widespread support from opposing parties partly because each political camp could read it in its own particular way - as a means for community-based self-help against more state welfare or as a means for building a more cooperative welfare system.

There is an inevitable ambivalence about innovations and their introduction to local welfare systems. On the one hand, they represent real new elements of support. On the other hand, their ultimate meaning only becomes apparent when taking account of the discursive framework in which they operate. Processes of popularising and mainstreaming innovations through negotiations will therefore mostly create hybrids of different ideas and inspirations. They are formed through a process of bricolage, a term from the famous anthropologist Lévi-Strauss (1966), which means to construct a new entity out of (mostly) old pieces. The nature of this bricolage can differ quite strongly. At one end of the spectrum, there are innovations copied in a straightforward manner, for example, through a franchising method. At the other end are innovations that are not scaled or diffused directly, but which have an indirect effect, by suffusing the values they build upon to other places. In between stand various innovations of which only parts are transferred, which are fused with local elements and possibly even imbued with different sets of values. It is no wonder that research on diffusion is methodologically so difficult. 


\subsection{Conclusions}

Using the metaphor of social innovations as messages allows integrating two aspects of social innovations that often get separated: (a) the content of innovative solutions - in this case in the field of welfare policies and services - and (b) social innovation as a process in which systems and politics-here, local welfare systems - deal with such solutions.

With respect to both content and policies, we systematically analysed evidence collected as part of WILCO to identify recurrent approaches and instruments used in local social innovations. The central aim was to draw messages on a more abstract level from our sample and to make them more overtly relevant both to academic debates and to practitioners working in other settings and countries. We classified them as five challenges: finding new ways to address users, innovating regulations and rights, ways of governance, modes of working and financing and the transformation of established local welfare mixes.

A significant message resulting from our work is that, if taken seriously, many new approaches are not the quick-fix solutions they were often intended to be. They are not available simply at the push of a button. There seem to be wide gaps between prevailing modes of policies, politics and organisation on the one hand and social innovations on the other. Bringing both sides together can demand a long learning process.

Despite their differences, the social policy community of theorists, experts and practitioners tends to operate within a shared paradigm that makes it difficult to incorporate innovations into the social policy vocabulary. To break through this, at least three prevailing perspectives must be questioned.

The first perspective to question is one that implies an exclusive link between social change and (national) state reform. If one revisits the history of the welfare state, it is to a large extent one of social innovations taken up or rejected, marginalised or mainstreamed. Social movements and organisations have always played an important role in inventing and creating welfare arrangements of their ownmutuals in the field of social security, cooperatives as early "social enterprises", voluntary associations establishing and running all kinds of services. Although much work in the third sector research community has examined this legacy of contributions from the third sector and civil society to welfare state development (see, e.g. the contributions in Evers and Laville 2004), the social policy research community has largely ignored it, treating welfare state reform almost exclusively as a set of top-down reforms.

Secondly, one should question interpretations of justice and stratification that lead to an emphasis on standardisation and uniform institutional arrangements, so characteristic of the basic belief system the modern welfare state was built upon (see Wagner 1994). It is crucial to reconsider how reliability and equality can be combined with room for social innovation and diversity. In order to achieve both, a balance must be struck between a guaranteed level of protection by regulations and the preservation of open spaces for change through innovation. 
Finally, many governance concepts still imply a central role for decision-making by powerful elites. Yet, if top-down and bottom-up initiatives are to be reconciled, public policies should be less about imposing change and more about preparing it through experiments and pilots. These should be designed to learn from social competences, accumulated through the change makers that have invented and carried them through (Then and Mildenberger 2014). In the debates on the persistence of hierarchy (Lynn 2011) and new forms of governance that are sensible for this challenge, some have labelled such an approach "democratic experimentalism" (Sabel 2012). Nudging change and preparing reform in this manner should be higher on the policy agenda.

These critical remarks point towards the conclusions of the second part of this chapter, which discussed how social innovations change once they become part of a local welfare system and spread from one place to another. Specifically, it focused on how diffusion of social innovations in local welfare is qualitatively distinct from the diffusion of other types of innovations. Typical of social innovations is their strong link to specific contexts. Exactly because they evolve within social relationships and rely upon the collaboration of various different actors, they are relatively hard to transplant from one context to another.

Furthermore, those who invented a new local social innovation are often not primarily interested in diffusion since they were originally motivated to solve a local problem. This is a fundamental difference with innovations in a business context because there the objective is to spread products as far and wide as possible.

The process of winning importance also appears to be different from the marketing of innovative products and purposeful mainstreaming by policymakers and administrators. Theoretically, one would expect the bottleneck in social innovation in a complex field such as welfare to be flaws in adaptation processes, but this does not appear to be the case in practice (as compared, for instance, to the diffusion of governmental innovations). One possible explanation is that social innovations tend to have a strong bottom-up element that allows them to evolve organically, with large contributions from local people and voluntary organisations. This is part of a transformative process prior to the adoption of an innovation that changes local social relations, for instance, by giving the voluntary sector a greater role in shaping local services. The actual innovation is just the final stage of this process and not necessarily the most important part of it.

The findings point towards a bias in the research on diffusion. It tends to emphasise the adoption of an innovation, failing to cover the process of transformation in social relations that occur ahead of adoption. By implication, it overstates the role of organisations involved in the direct transfer of innovations (particularly professional networks) and underestimates the role of actors involved in the wider process of local transformation, including citizens and voluntary organisations.

Arguably, the cumulative effect of small initiatives is of far greater importance to society than the few examples that achieve wider and more visible impact. In any case, research on social innovation should not restrict its focus on success (in the sense of being taken up and mainstreamed). Where social innovations survive in more difficult environments, their impact on mainstream welfare is more indirectas one element in a cultural turn that may be quietly successful in the long run, even if many innovations fail at the first attempt. 
Open Access This chapter is distributed under the terms of the Creative Commons AttributionNonCommercial 4.0 International License (http://creativecommons.org/licenses/by-nc/4.0/), which permits any noncommercial use, duplication, adaptation, distribution and reproduction in any medium or format, as long as you give appropriate credit to the original author(s) and the source, a link is provided to the Creative Commons license and any changes made are indicated.

The images or other third party material in this chapter are included in the work's Creative Commons license, unless indicated otherwise in the credit line; if such material is not included in the work's Creative Commons license and the respective action is not permitted by statutory regulation, users will need to obtain permission from the license holder to duplicate, adapt or reproduce the material.

\section{References}

Barber, B. (2013). If mayors ruled the world. Dysfunctional nations, rising cities. Yale: Yale University Press.

Boltanski, L., \& Chiapello, E. (2005). The new spirit of capitalism. London: Verso.

Bonoli, G. (2005). The politics of the new social policies: Providing coverage against new social risks in mature welfare states. Policy \& Politics, 33(3), 431-449.

Bovenberg, A. L. (2008). The life-course perspective and social policy: An overview of the issues. CESifo Economic Studies, 54(4), 593-641.

Boyle, D., Coote, A., Sherwood, C., \& Slay, J. (2010). Right here, right now: Taking co-production into the mainstream. London: NESTA and NEF. http://www.neweconomics.org/publications/ right-here-rightnow.

Brandsen, T., \& Honingh, M. (2013). Professionals and shifts in governance. International Journal of Public Administration, 36(12), 876-883.

Brandsen, T., \& Kim, S. (2010). Contextualizing the meaning of public management reforms: A comparison of the Netherlands and South Korea. International Review of Administrative Sciences, 76(2), 367-386.

Coqblin, A., \& Fraisse, L. (2014). Le temps pour toit-Time for a roof. In A. Evers, B. Ewert, \& T. Brandsen (Eds.), Social innovations for social cohesion: Transnational patterns and approaches from 20 European cities. Liége: EMES European Research Network asbl. http:// www.wilcoproject.eu/downloads/WILCO-project-eReader.pdf, 93-95.

Dolowitz, D. P., \& Marsh, D. (2000). Learning from abroad: The role of policy transfer in contemporary policy-making. Governance, 13(1), 5-24.

Evers, A., \& Ewert, B. (2015). Social innovation for social cohesion. In A. Nicholls, J. Simon \& M. Gabriel (Eds.), New frontiers in social innovation research. Basingstoke: Palgrave.

Evers, A., \& Guillemard, A. M. (2013). Marshall's concept of citizenship and contemporary welfare reconfiguration. In A. Evers \& A. M. Guillemard (Eds.), Social policy and citizenship: The changing landscape (pp. 3-34). Oxford: Oxford University Press.

Evers, A., \& Laville, J.-L. (2004). The third sector in Europe. Cheltenham: Edward Elgar.

Evers, A., Ewert, B., \& Brandsen, T. (Eds.) (2014). Social innovations for social cohesion: Transnational patterns and approaches from 20 European cities. Liége: EMES European Research Network asbl. http://www.wilcoproject.eu/downloads/WILCO-project-eReader.pdf.

Goldsmith, S. (2010). The power of social innovation. San Francisco: Jossey Bass.

Handler, J. F. (2004). Social citizenship and workfare in the United States and Western Europe. The paradox of inclusion. Cambridge: Cambridge University Press.

Johnson, S. (2010). Where good ideas come from. The natural history of innovation. London: Penguin.

Jenson, J. (2013). Social Innovation. Resesigning the Welfare Diamond. http://www.transitsocialinnovation.eu/content/original/Book\%20covers/Local\%20PDFs/100\%20SF\%20Jenson $\% 20$ Social\%20innovation $\% 20$ redesigning\%20the $\% 20$ wlfare $\% 20$ diamond $\% 202013$.pdf.

Lévesque, B. (2013). Social innovation in governance and public management systems. In F. Moulaert, D. MacCallum, A. Mehmood, \& A. Hamdouch (Eds.), Handbook on social innovation: 
Collective action, social learning and transdisciplinary research (pp. 25-39). Cheltenham: Edward Elgar.

Lévi-Strauss, C. (1966). The savage mind. Chicago: University of Chicago Press.

Lynn, L. E. (2011). The persistence of hierarchy. In M. Bevir (Ed.), The SAGE handbook of governance (pp. 218-236). London: Sage.

Moore, M., \& Hartley, J. (2009). Innovations in governance. In S. Osborne (Ed.), The new public governance? Emerging perspectives on the theory and practice of public governance (pp. 52 71). New York: Routledge.

Morel, N., Palier, B., \& Palme, J. (Eds.). (2012). Towards a social investment welfare state? Ideas, policies and challenges. Bristol: Policy Press.

Moulaert, F., Martinelli, F., Swyngedouw, E., \& Gonzalez, S. (2005). Towards alternative model(s) of local innovation. Urban Studies, 42(11), 1969-2005.

Nowotny, H. (1997). Die Dynamik der Innovation. Über die Multiplizität des Neuen. In: W. Rammert/G. Bechmann (Hrsg.), Technik und Gesellschaft Jahrbuch 9 Innovation - Prozesse, Produkte, Politik. Frankfurt a. M.: Campus Verlag, S. 33-54.

Osborne, S., \& Strokosch, K. (2013). It takes two to tango? Understanding the co-production of public services by integrating the services management and public administration perspectives. British Journal of Management, 24(1), 31-47.

Pollitt, C., \& Bouckaert, G. (2004). Public management reform: A comparative analysis. Oxford: Oxford University Press. (First edition 2000).

Radaelli, C. M. (2000). Policy transfer in the European Union: Institutional isomorphism as a source of legitimacy. Governance, 13(1), 25-43.

Rogers, E. M. (1962). Diffusion of innovations. New York: The Free Press.

Sabel, C. (2012). Dewey, democracy, and democratic experimentalism. Contemporary Pragmatism, 9(2), 35-55.

Schmidt, V. A. (2010). Taking ideas and discourse seriously: Explaining change through discursive institutionalism as the fourth 'new institutionalism'. European Political Science Review, 2(1), $1-25$.

Scott, J. C. (1998). Seeing like a state: How certain schemes to improve the human condition have failed. Yale: Yale University Press.

Then, V., \& Mildenberger, G. (2014). The central role of civil society for social innovation. Paper given at the ISTR World Conference, Münster, 24 July 2014.

Verschuere, B., Brandsen, T., \& Pestoff, V. (2012). Co-production: The state of the art in research and the future agenda. VOLUNTAS: International Journal of Voluntary and Nonprofit Organizations, 23(4), 1083-1101.

Wagner, P. (1994). A sociology of modernity: Liberty and discipline. London: Routledge.

Zapf, W. (1989). Über soziale Innovationen. Soziale Welt, 40(1/2), 170-183. 